\title{
Venlafaxine Hydrochloride
}

National Cancer Institute

\section{Source}

National Cancer Institute. Venlafaxine Hydrochloride. NCI Thesaurus. Code C29540.

A synthetic ethyl-cyclohexanol derivative used for the treatment of depression,

Venlafaxine Hydrochloride is metabolized to O-desmethylvenlafaxine, which potentiates

CNS activity. Both venlafaxine and its active metabolite inhibit neuronal reuptake of norepinephrine, dopamine, and serotonin. (NCI04) 